\title{
ATROFIA DE DISCO ÓPTICO EN BANDA SECUNDARIA A COMPRESIÓN POR SUBEPENDIMOMA VENTRICULAR
}

\author{
BAND ATROPHY OF THE OPTIC DISC SECONDARY TO \\ VENTRICULAR SUBEPENDYMOMA COMPRESSION
}

\author{
DAPENA-SEVILLA I ${ }^{1}$, DRAKE-RODRÍGUEZ P¹, GUTIÉRREZ-ORTIZ C ${ }^{2}$, BOLÍVAR G ${ }^{1}$, \\ CASTEJÓN M${ }^{1}$, TEUS-GUEZALA MA ${ }^{2}$
}

\section{RESUMEN}

Caso clínico: Varón de 42 años con atrofia óptica en banda o en «pajarita» derecha con hemianopsia homónima derecha. En la tomografía computerizada (TC) se observa una lesión calcificada a nivel de hipocampo izquierdo. Se realizó craneotomía y resección tumoral con diagnóstico definitivo de subependimoma de asta temporal de ventrículo lateral izquierdo.

Discusión: Las lesiones de la cintilla óptica son entidades clínicas poco frecuentes que cursan con hemianopsia homónima y atrofia óptica en banda o en «pajarita» contralateral. El subependimoma es un tumor infrecuente y benigno, que se asocia típicamente con el sistema ventricular.

Palabras clave: Atrofia óptica, atrofia en banda, cintilla óptica, vía visual, subependimoma.

\begin{abstract}
Case report: A 42-year-old man was diagnosed with band or «bow tie» optic atrophy with a right homonymous hemianopia. Computerized tomography (CT) revealed a calcified lesion in the left hippocampus. Craniotomy and tumor resection were performed. The biopsy revealed a subependymoma of the temporal horn of the left ventricular system.

Discussion: Optic tract lesions are uncommon clinical entities, in which homonymous hemianopia and contralateral band optic atrophy are characteristic. Subependymomas are infrequent and benign tumors that are typically associated with the ventricular system (Arch Soc Esp Oftalmol 2007; 82: 567-570).
\end{abstract}

Key words: Optic atrophy, band atrophy, optic tract, visual pathway, subependymoma.

\section{INTRODUCCIÓN}

La atrofia óptica en banda o en «pajarita» es una franja horizontal central pálida, que respeta los polos superior e inferior del disco óptico, y es el tipo de atrofia retrógrada que producen las afecciones quiasmáticas de forma bilateral y las lesiones de la cintilla óptica en el nervio óptico contralateral (1).

\footnotetext{
Recibido: 31/5/06. Aceptado: 25/7/07.

Servicio de Oftalmología. Hospital Universitario Príncipe de Asturias. Universidad de Alcalá. Alcalá de Henares. Madrid. España.

1 Licenciado en Medicina.

2 Doctor en Medicina.

Correspondencia:

Isabel Dapena Sevilla

C/. Camino Sur, 18

28109 Madrid

España

E-mail: isadap@terra.es
} 


\section{CASO CLÍNICO}

Varón de 42 años, asintomático, fue valorado oftalmológicamente para revisión de su diabetes tipo II de 3 años de evolución. En la exploración física la agudeza visual corregida fue de 1.0 en ambos ojos. El polo anterior estaba dentro de la normalidad y la presión intraocular fue de $16 \mathrm{mmHg}$ en ambos ojos. La motilidad intrínseca y extrínseca fue normal. La oftalmoscopia indirecta mostró un nervio óptico derecho con atrofia en banda o en «pajarita» (fig. 1) y papila izquierda (fig. 2) que se describió como pálida; no había signos de retinopatía diabética.

Se realizó un campo visual (Humphrey 30-2 test Allergan Humphrey, San Leandro, California, USA) donde se apreció una hemianopsia homónima derecha (fig. 3). Ante la sospecha de lesión ocupante de espacio intracraneal, se realizó una Tomografía computerizada (TC) cerebral en el que se observó una calcificación de $2 \mathrm{~cm}$ de diámetro en relación con amígdala y cabeza del hipocampo izquierdo (fig. 4). La resonancia magnética cerebral mostró una lesión heterogénea en la cabeza del hipocampo izquierdo, con calcificación y un área hemorrágica adyacente.

El test de colores fue normal. En la arteriografía cerebral y mapeo vascular prequirúrgico, el paciente presentó una reacción alérgica al contraste con manifestaciones cutáneas, que cedió tras el tratamiento con antihistamínicos.

Se intervino quirúrgicamente mediante craneotomía y se realizó una resección completa de la

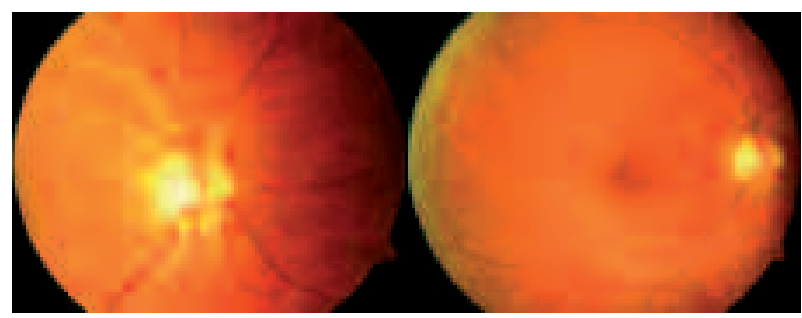

Fig. 1: Atrofia en banda papilar derecha.

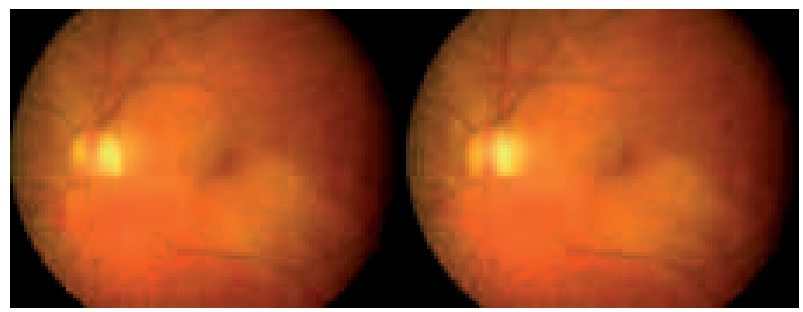

Fig. 2: Palidez papilar izquierda.
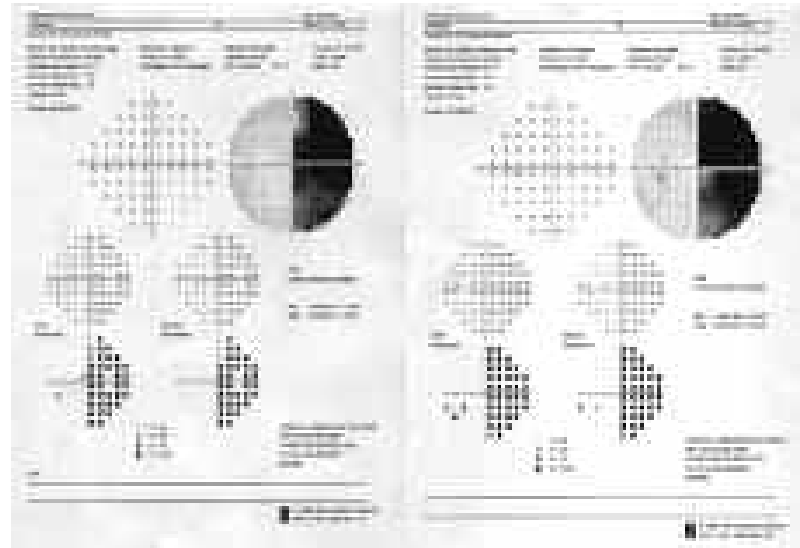

Fig. 3: Campo visual con hemianopsia homónima derecha.

lesión. El estudio anatomopatológico de la misma reveló un subependimoma. El diagnóstico definitivo fue de subependimoma de asta temporal de ventrículo lateral izquierdo con afectación de vía retroquiasmática y atrofia óptica en banda izquierda.

En la última exploración oftalmológica sigue sin cambios, mantiene la hemianopsia homónima derecha

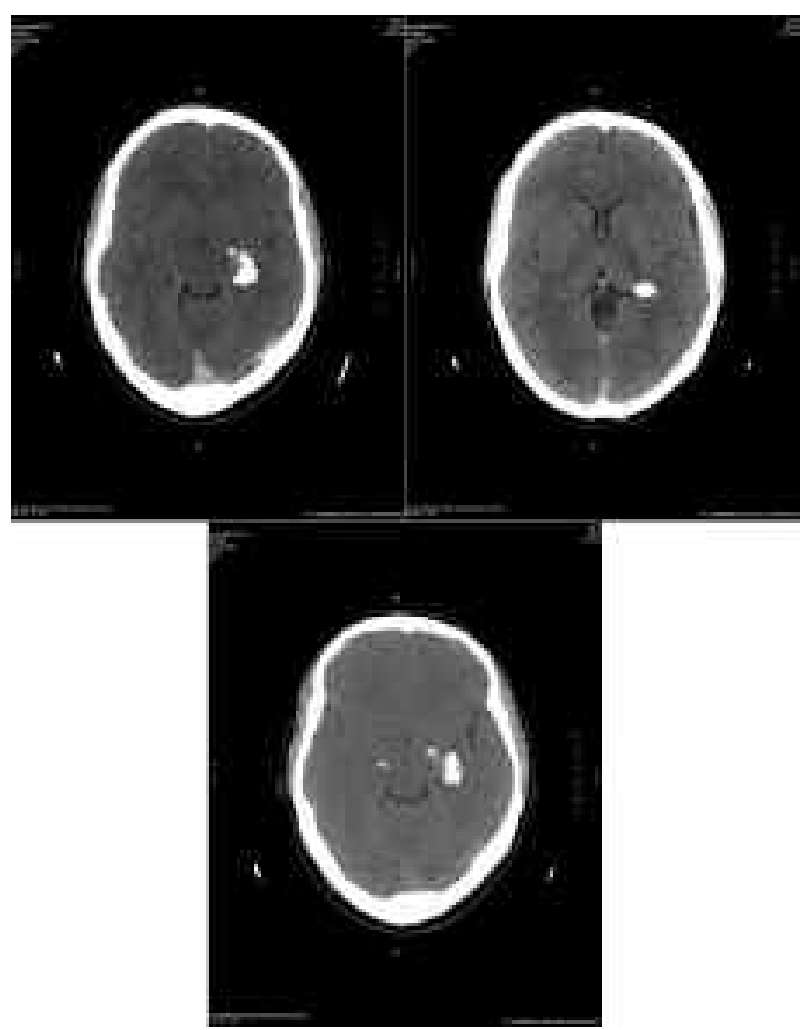

Fig. 4: Imágenes de TC con lesión calcificada en hipocampo izquierdo. 
en la campimetría, los nervios ópticos con el mismo grado de atrofia y el resto de la exploración es normal.

\section{DISCUSIÓN}

Las afecciones de la cintilla óptica o del cuerpo geniculado lateral producen una atrofia en banda del disco óptico contralateral y una palidez temporal del disco ipsilateral. Su explicación radica en que los axones procedentes de las hemirretinas nasal y temporal tienen una distribución diferente en el nervio óptico (1).

Puede asociarse con patología compresiva contralateral, traumática, desmielinizante y lesiones o malformaciones vasculares contralaterales a la cintilla óptica (2). Se ha descrito como componente del síndrome de hipoplasia hemióptica homónima asociada a heterotopia cortical focal (3).

Se han descrito múltiples agentes causales de compresión del nervio óptico: adenomas hipofisarios, meningiomas, del tubérculo selar, del ala menor del esfenoides e intracanaliculares, craniofaringiomas, ependimomas, carcinomas nasofaríngeos, aneurismas, procesos inflamatorios (mucoceles, paquimeningitis), enfemedades óseas (osteopetrosis, craneostosis), hidrocefalia, angiomatosis encéfalotrigeminal de Sturge-Weber y dolicoectasia arterial, entre otras.

Las lesiones de la cintilla óptica son entidades clínicas infrecuentes, que presentan como característica más típica la presencia de un campo visual con un defecto hemianópsico homónimo que puede ser completo o incompleto. Cuando es incompleto presenta relativa incongruencia, y cuando es completo asocia defecto pupilar aferente relativo contralateral. La congruencia o simetría entre ambos ojos es menor cuanto más anterior y mayor cuanto más posterior sea su situación. Con una duración suficiente, el fondo contralateral a la lesión demuestra atrofia en banda o en «pajarita» del nervio y capa de fibras nerviosas y una palidez temporal del nervio óptico ipsilateral (4).

En nuestro caso estaríamos ante un paciente con lesión de la cintilla óptica secundaria a una patología tumoral compresiva que provoca una hemianopsia homónima derecha simétrica y que no tiene valor localizador por ser completa. Asimismo presentó una atrofia óptica en banda derecha y palidez del nervio óptico izquierdo. Todo ello nos hizo realizar el diagnóstico de afectación de la vía retroquiasmática.

La afectación de la cintilla óptica no produce disminución de la agudeza visual, salvo que sea bilateral, y la percepción cromática es asimismo normal en la mayoría de los casos (4), como en nuestro paciente. La lesión de la cintilla óptica o del cuerpo geniculado lateral es la única hemianopsia homónima que asocia atrofia óptica.

Los subependimomas son tumores infrecuentes $(0,51 \%$ de todos los tumores del sistema nervioso central), son benignos y de crecimiento lento. Como en nuestro caso, se asocian típicamente con el sistema ventricular y suelen diagnosticarse cuando presentan clínica por expansión intracraneal. Son más frecuentes en varones de mediana edad (5).

El papel de la radioterapia no está bien definido, en algunas ocasiones se ha utilizado como tratamiento coadyuvante de lesiones con resección subtotal o lesiones recurrentes, pero no se ha establecido ningún consenso (5).

Las lesiones compresivas expansivas intracraneales pueden ser una amenaza vital para el paciente, $\mathrm{y}$ susceptibles de tratamiento neuroquirúrgico, siendo de máxima importancia la detección precoz de sus síntomas y signos.

\section{BIBLIOGRAFÍA}

1. Arruga J. Neuropatías Ópticas: Diagnóstico y tratamiento. Sociedad Española de Oftalmología; 2002.

2. Hoyt WF, Rios-Montenegro EN, Behrens MM, Eckelhoff RJ. Homonymous hemioptic hypoplasia. Fundoscopic features in standard and red-free illumination in three patients with congenital hemiplegia. Br J Ophthalmol 1972; 56: 537-545.

3. Turbin RE, St Louis L, Barr D, Kupersmith MJ. Monocular band optic atrophy. J Neuroophthalmol 1998; 18: 242245.

4. Newman SA, Miller NR. Optic tract syndrome. Neuroophthalmologic considerations. Arch Ophthalmol 1983; 101: 1241-1250.

5. Ragel BT, Osborn AG, Whang K, Townsend JJ, Jensen RL, Couldwell WT. Subependymomas: an analysis of clinical and imaging features. Neurosurgery 2006; 58: 881 890. 